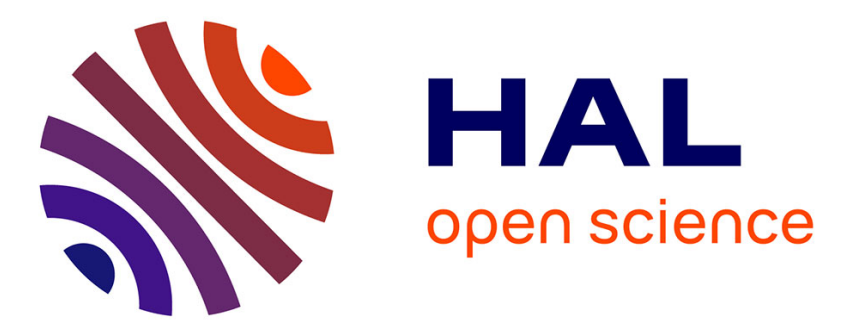

\title{
Impact on 3D Carbon/Carbon Composites : a Meso-Scale Approach
}

\author{
O. Allix, M. Dommanget, Michel Gratton, P. Héreil
}

\section{To cite this version:}

O. Allix, M. Dommanget, Michel Gratton, P. Héreil. Impact on 3D Carbon/Carbon Composites: a Meso-Scale Approach. Journal de Physique IV Proceedings, 1997, 07 (C3), pp.C3-675-C3-680. 10.1051/jp4:19973115 . jpa-00255400

\section{HAL Id: jpa-00255400 https://hal.science/jpa-00255400}

Submitted on 1 Jan 1997

HAL is a multi-disciplinary open access archive for the deposit and dissemination of scientific research documents, whether they are published or not. The documents may come from teaching and research institutions in France or abroad, or from public or private research centers.
L'archive ouverte pluridisciplinaire HAL, est destinée au dépôt et à la diffusion de documents scientifiques de niveau recherche, publiés ou non, émanant des établissements d'enseignement et de recherche français ou étrangers, des laboratoires publics ou privés. 


\title{
Impact on 3D Carbon/Carbon Composites: a Meso-Scale Approach
}

\author{
0. Allix*, M. Dommanget**, M. Gratton and P.L. Héreil ${ }^{* * *}$
}

Laboratoire de Mécanique et Technologie, ENS Cachan/CNRS/Université Paris 6, 61 av du Président Wilson, 94230 Cachan, France

*Université d'Evry-Val-d'Essonne, I.U.T.G.M.P., 2 cours Monseigneur Roméro, 91000 Evry cedex, France

\author{
** Aérospatiale les Mureaux, 96 Route de Verneuil, 78133 Les Mureaux cedex, France \\ *** Centre d'Étude de Gramat, 46500 Gramat, France
}

\begin{abstract}
A method for the fracture prediction under dynamic loading of small structures made of a 3D Carbon/Carbon composite is proposed. Due to the length scale of the loading, the notion of a homogenized material is meaningless; our choice herein is to model, identify and compute the material at an intermediate or meso scale (fibre strands - matrix blocks). Our idea is that, due to the smallness of the meso scale, the previous description of the damage mechanisms should be valid even for high-rate loading. This meso-modelling is based on static and dynamic tests. Changing scale methods are applied to identify the mesoscopic model parameters (damage - plasticity - porosity) from static tests. The results from the dynamic computing of plate/plate tests confirm this method.
\end{abstract}

\begin{abstract}
Résumé: Une méthodologie pour la prévision de la rupture sous choc, de pièces de petites dimensions en matériaux $3 \mathrm{D} \mathrm{C} / \mathrm{C}$, est proposée. Pour ce type de sollicitations, la notion de matériau homogène équivalent est inadaptée. Aussi nous avons choisi de modéliser et d'identifier le matériau à l'échelle de ses méso-constituants: torons et blocs de matrice. Les calculs sont également effectués à cette échelle. Le méso-modèle développé se nourrit d'informations qualitatives obtenues par des essais statiques et dynamiques mais est identifié en statique. Un outil de changement d'échelle est utilisé, de façon itérative, pour identifier les paramètres du méso-modèle (torons-blocs de matrice). Des premières simulations dynamiques d'essais d'impact plaque/plaque montrent l'intérêt de la démarche.
\end{abstract}

\section{INTRODUCTION}

This work, conducted jointly by the L.M.T., the Aérospatiale Les Mureaux and the C.E.G., refers to the study of the dynamic behaviour up to fracture of a 3D C/C composite. This composite, named Bloc 300 , presents an orthogonal structure. The objective herein is to foresee the response of small pieces under highspeed loadings. We have, therefore, proposed and identified a model of behaviour. This model, included in an explicit dynamic finite element program, should allow us to estimate the damage level of any small structure in consequence of an aggression.

The loadings under consideration present a characteristic length comparable with those of the Representative Elementary Volume of the material. The use of the homogenized material is therefore meaningless. Another aspect of this study is that, though quite low, the ultimate shear stress takes a prominent part in the load transfer. Indeed, even a homogeneous loading generates very high shear strain rates in the material.

The first key-point is thus to define a scale, compatible not only with a correct description of the behaviour but also with a structural dynamic analysis. One pragmatic answer is to define a scale characteristic of the main damage mechanisms. For the 3D composites, between the macro-scale of the structure and the microscale of the fibres, we can easily see the intermediate scale (or meso-scale) of yarns of fibre and different blocks of matrix. At this scale, the main damage mechanisms (fibre yarn fracture, matrix block deterioration) appear to be nearly uniform in each meso-constituent, at least under quasi-static loadings. Our idea is that, due to the smallness of the meso-constituents, a homogeneous modelling of damage mechanisms by meso-constituents should be valid even for highrate loadings.

After having determined the meso-constituents, the experimental data that allow us to intuite the main characteristics of the mechanical behaviour are presented. The static and dynamic tests, on the whole, are used to propose a first non-linear modelling of the behaviour of the meso-constituents. The static tests [1], inspired by is previous study on another 3D C/C [2], [3], allow exciting the main damage, anelasticity, and/or friction mechanisms, up to their ultimate values. Tests on specimens, for which a yarn direction has previously been removed by machining, thereby allowing us to access information on the effects of compaction.

The main model parameters are identified from static tests. The validity of the approach is then tested by means of comparison between tests and computing for the case of plate/plate impacts in a yarn direction. 


\section{DEFINITION OF THE MESO-CONSTITUENTS}

The directions $\mathrm{x}$ and $\mathrm{y}$ are equivalent. The periodicities in the $\mathrm{x}, \mathrm{y}$ and $\mathrm{z}$ directions are $1.6 \mathrm{~mm}, 1.6 \mathrm{~mm}$ and $0.324 \mathrm{~mm}$ respectively. The middle section of the $\mathrm{z}$ yarns is aqual to $0.8 \times 0.8 \mathrm{~mm}^{2}$; the section of the $\mathrm{x}$ and $\mathrm{y}$ yarns is $0.68 \times 0.157 \mathrm{~mm}^{2}$. The presence of pores and oriented cracks in some matrix blocks is taken into account by the local transversely isotropic behaviour. The elementary cell is composed of 3 kinds of meso-constituents: the yarns, the isotropic matrix blocks and the anisotropic blocks - the isotropic plane is associated to the main cracking plane. The shapes of the constituents are presented in Fig 1-2.

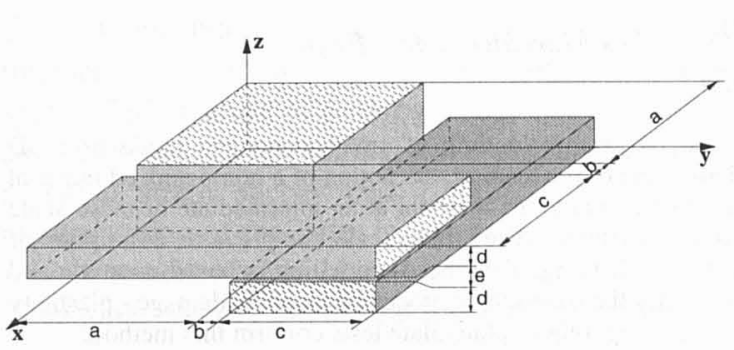

Figure 1: Yarns

$a=0.4, b=0.06, d=0.0785, e=0.005, c=a-b(\mathrm{~mm})$

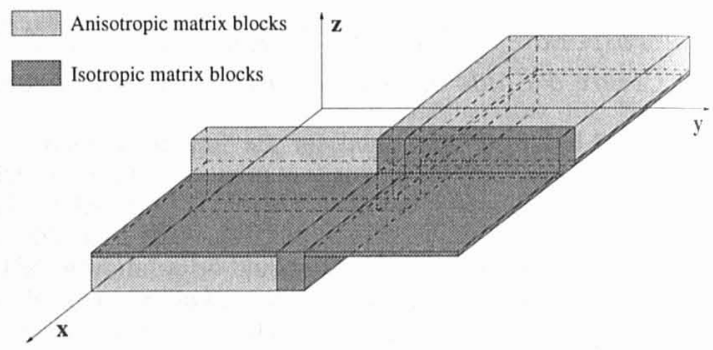

Figure 2: Geometry of the meso-constituents modelling the matrix

\section{TESTS AND MESO-MODELLING OF THE NON-LINEAR BEHAVIOUR}

The main static (L.M.T.) and dynamic (C.E.G.) experimental data supporting the proposed non-linear model of the various meso-constituent behaviours are presented.

\subsection{Static tests}

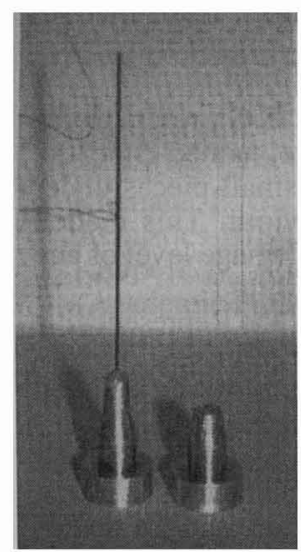

Figure 3:

Tensile test on $\mathrm{z}$ yarn

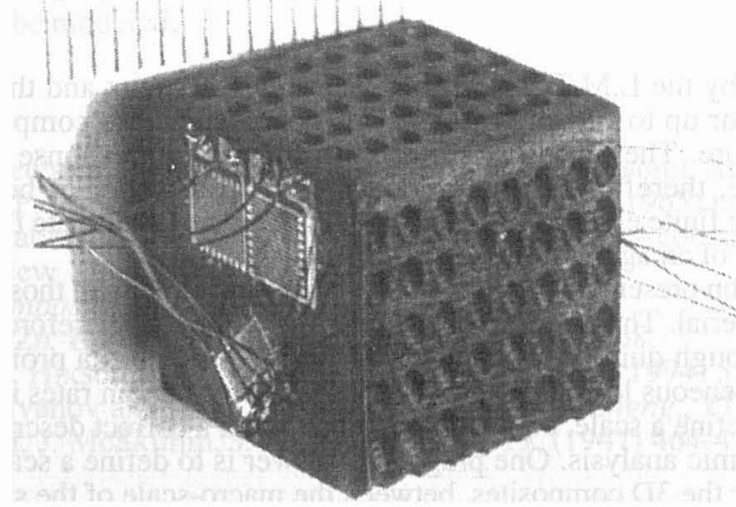

Figure 4: Non-standard compression testing piece ( $z$ yarns taken off by drilling)

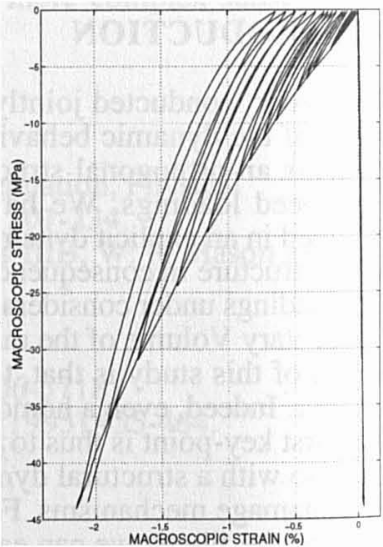

Figure 5: Compression in the $\mathrm{z}$ direction ( $\mathrm{z}$ yarns taken oli)

Sensitivity curves linking local parameters to global parameters show that the macroscopic modulus in the different yarn directions depend mainly on the longitudinal yarn modulus. The yarn behaviour in their axis and the macroscopic behaviour will have the same form: elastic brittle under tensile stress and elastic with damage under compression stress. The tensile (Fig3) and the torsion tests on yarns give the Poisson's ratio $v_{13 t}$ and the shear modulus $\mathrm{G}_{\mathrm{o} 13 \mathrm{t}}$.

The level of the shear stress in the matrix blocks is fairly high in the $45^{\circ}$ tests (Fig 4 and Fig 10.3). Considering the loss of global stiffness and the macroscopic residual strains, the behaviour of the matrix blocks is assumed to be elastic plastic with damage.

The compression test (Fig 5) on the drilled Bloc300 compresses the matrix blocks and the yarns in their isotropic plane. A unilateral aspect and non-linear elasticity appear during the unloading. The effect of porosity is also exposed. 


\subsection{The dynamic tests}

The dynamic tests carried out at C.E.G., on the Bloc300, consist of plate/plate impact fitted out with different kinds of metrology: VISAR interferometry, high-speed cinematography and piezoelectric pressure gauges PVFD [4]. Other tests with recovery of the testing piece allow an analysis of the fracture.

These tests have been conducted on testing pieces in 3 different planes of the material: normal $\mathrm{x}, \mathrm{z}$ and $\mathrm{xy}$ $\left(45^{\circ}\right.$ from the directions of the yarns). The main features that emerge from the tests parallel to a yarn direction are:

-the velocities of the shock waves are heterogeneous (Fig 7),

-the increasing of the velocity of the shock waves is a function of the jump of the particular velocity (Fig 10),

-the interpretation of the fracture location in the yarn parallel to the direction of the impact (Fig 6) cannot be done without taking into account the loading transfer,

-a speed slope precedes the shock wave.

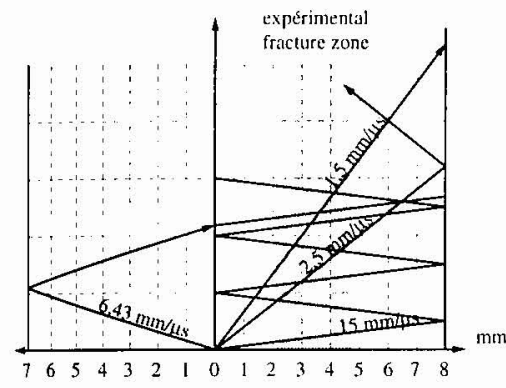

Figure 6: Characteristic diagram

Figure 7 (at right): Swecping slit camcra: heterogeneity of the velocities of the shock waves.

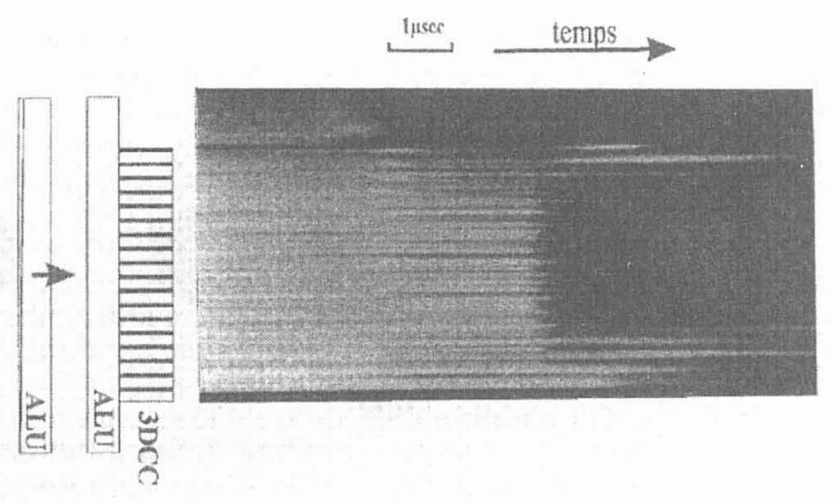

\subsection{Meso-modelling of the behaviour of the different constituents}

The main features of the meso-constituents are the damage, the anelasticity, the compaction with anisotropic effects and a unilateral aspect resulting from the opening and the closing of the cracks. The tools used to model these different aspects are summarily presented below.

The damage indicators [5] are associated with the variations of the stiffness modulus. The damage variables $\mathrm{d}_{\mathrm{i}}$ are uniform in the meso-constituents. They are directed by the average of the damage restitution rate $\mathbf{Y}_{\mathrm{i}}$, on the meso-constituent.

The mesoscopic modelling of the anelasticity is inspired by the damage's, that is to say that the internal variable associated with the cumulative plastic strains is homogeneous on each meso-constituent and governed by an equivalent average stress.

The bulk modulus, for negative pressure, is not affected by the damage variable $d$ (resistance of the confined material). The unilateral character is thus introduced by separating the free energy relative to a positive pressure from the energy relative to a negative pressure. In this case, the state law is chosen as follows:

$$
P=\left\{C_{n}^{2} \cdot \rho_{0} \cdot\left\langle\varepsilon^{n}\right\rangle_{-}\right\} /\left\{\left(I+a \cdot \cdot\left\langle\varepsilon^{n}\right\rangle_{-}\right)^{2}\right\}
$$

This expression is established from the state law relative to the impact test: $U_{s}=C_{o}+a \cdot U_{p}$, the conservative equations at the discontinuity allowing the transition from the variables [jump of particular velocity, shock wave velocity\} to the variables \{jump of pressure, jump of bulk strain\}. Considering that this expression is almost equal to the one relative to a quasi-static isotherm transformation, it thus links the pressure and the bulk strain in a continuous manner.

-The initialy isotropic matrix blocks are elastic-plastic with damage, with one damage variable and one plasticity variable. The free energy is:

$$
\left.\rho \Psi=\frac{1}{2} \frac{<\sigma^{v}>_{+}^{2}}{k(d)}+E_{d}\left(<\sigma^{v}\right\rangle_{-}\right)+\frac{1}{2} \frac{\sigma^{D}: \sigma^{D}}{2 G(d)}+L(p)
$$

The plasticity is assumed isotropic and governed by the deviatoric stress. The yield function is:

$$
\mathrm{f}=\sigma_{\mathrm{eq}}-\mathrm{R}-\mathrm{R}_{\mathrm{o}} \text { avec } \sigma_{\mathrm{eq}}=\frac{1}{\mathrm{~V}(\Omega)} \int_{\Omega} \sqrt{\operatorname{tr}\left[\sigma^{\mathrm{D}} \sigma^{\mathrm{D}}\right]} \cdot \mathrm{d} \Omega
$$


-The yarn is initially transverse isotropic. The damage is characterized by three variables: one affecting the longitudinal modulus and two affecting the shear modulus. Non-linear elasticity is introduced in the yarn plane.

-The behaviour of the anisotropic matrix blocks is non-linear elastic, plastic and porous, with the tensile strength in the isotropic axis being nil.

\section{IDENTIFICATION OF THE MESOSCOPIC BEHAVIOUR}

The behaviour of the meso-constituents is characterized by different parameters that allow to describ the elasticity, the evolution of anelasticity, damage and the effects of compaction. The problem is to determine the set of parameters which enable closely reproducing the set of experimental information. In the case of periodic material, the asymptotic development technique allows changing scale [6]. The identification is performed in two different steps on the cells presented in Fig 9.

-Iterative determination of the initial elastic behaviour with a technic of sensibility associated with the tool for changing scale, taking into account the macroscopic elastic modulus.

- Determination of the parameters relative to the not-linear behaviour after a hierarchical organization of the mechanisms [1]. The tool of changing scale utilizes step by step the linear incremental behaviour operator determined explicitly from the solution to the problem in the previous deformation step (Fig 10).
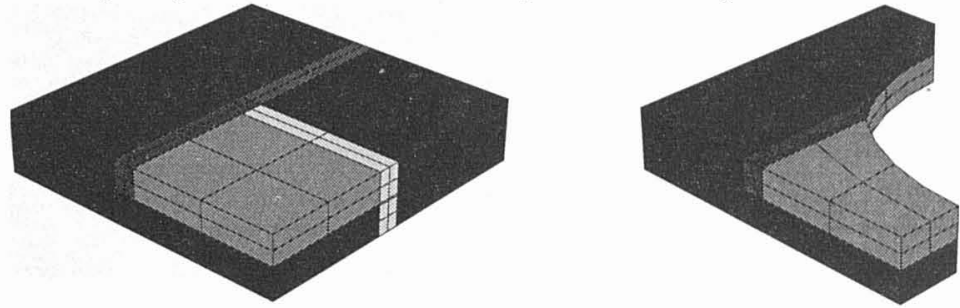

Figure 9: Elementary cells

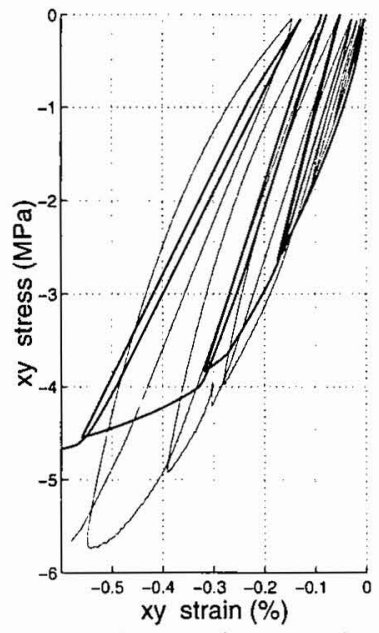

Compression at $45^{\circ}$ in the orthotropic plane yz (z yarns removed).

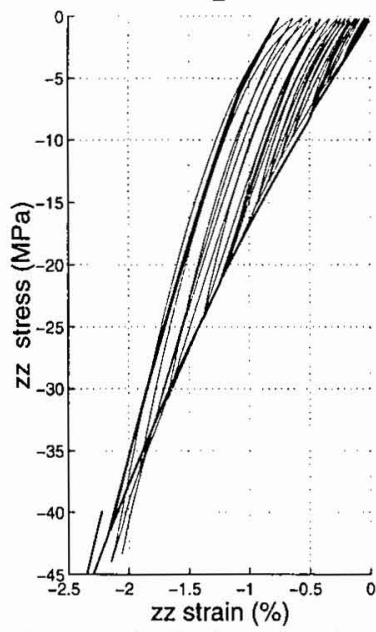

Compression in the $\mathrm{z}$ direction (z yarns removed).

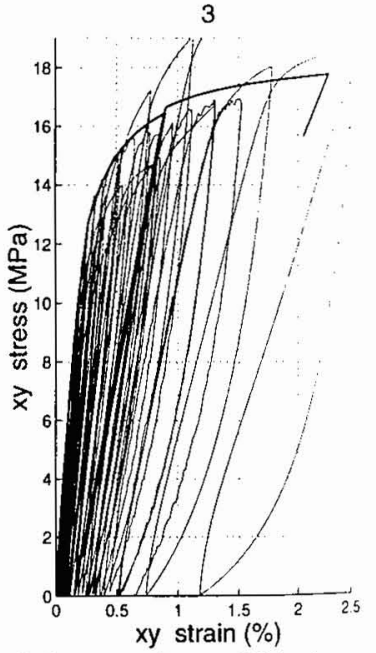

Tensile/compression at $45^{\circ}$ in the orthotropic plane $x y$.

Figure 10: Computations (bold lines) and tests (thin lines)

\section{DYNAMIC: COMPARISONS BETWEEN TESTS/COMPUTATIONS}

The state of the strains in plate-plate impact tests on homogeneous material, before the lateral waves, is uniaxial. In the case of the Bloc 300 impacted in a yarn direction, it's the average strain which is uniaxial. A simplified model based on a hypothesis of uniaxial propagation of the waves, the stress state being multiaxial, has been developded. In this model, the different meso-constituents are linked together by an interphase of which the properties are deduced from those of the matrix. In order to take into account the large displacements, a friction model has been introduced at the interphase. 


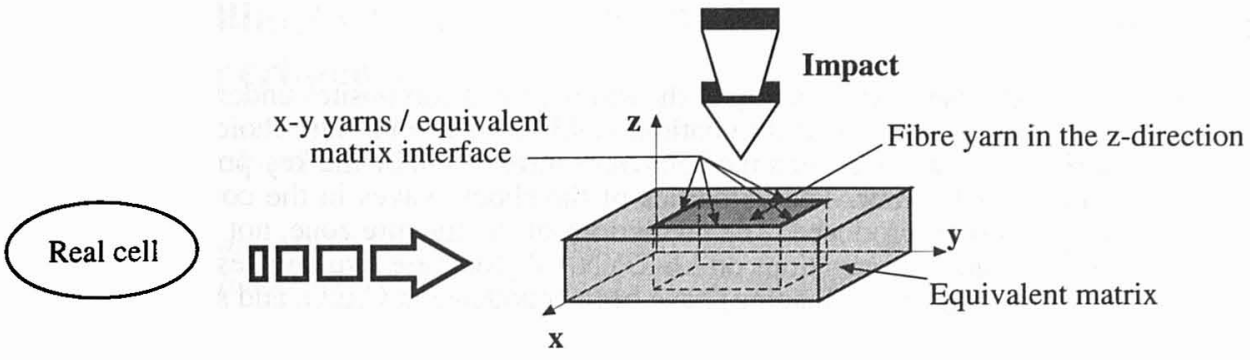

The spatial discretization of the problem is thus:

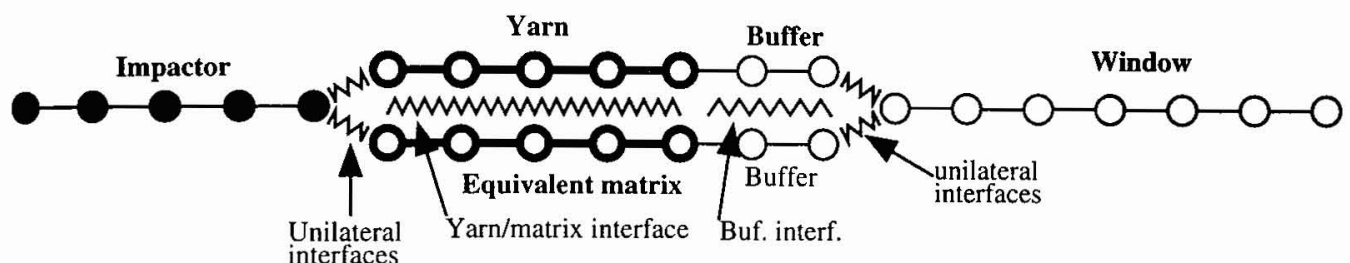

The time scheme is the central difference method. A dumping of the mass matrix allows to come down to a totally explicit problem conditionally stable. The behaviour of the matrix being porous, bulk viscosity [7] is introduced to express the physics of the shock [8]. This parameter one is adjusted in order to follow the Rayleigh line [9] during the discontinuity. The behaviour of the different constituents is based on the statics study. The impactor and the window are considered elastic linear on the speed range under consideration. Comparisons between computations and experimental results of the particular velocity at the back of the buffer, for three different velocities of the impactor, are presented in Fig 11.

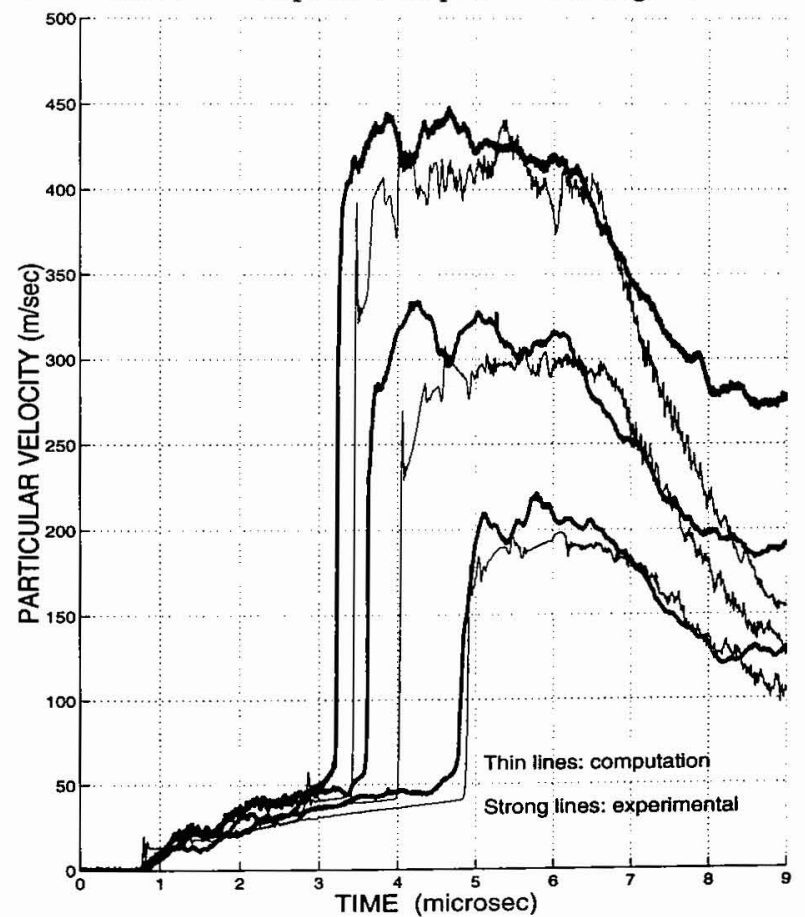

Figure 11: Particular velocity at the back of the buffer. Impact in the $\mathrm{z}$ direction. Comparison between computations/tests 


\section{CONCLUSION}

The methodology proposed for the study of the tridirectional composites under shock, extending from the modelling of the meso-constituents to simulation, yields good results. The choice of the scale proper to the material to describe the static and dynamic behaviour turns out to be the key point; no speed effect has been introduced into the behaviour. The velocities of the shock waves in the constituents as particular velocities have been properly reproduced. The predictions of the fracture zone, not presented in this paper, are promising. Tridimensional computations on LS-DYNA3D for these dynamic tests are being perforned. Other tests with thin impactors (pulse loading) have been conducted at C.E.G. and should allow to validate the model.

\section{References}

[1] O. Allix, M. Gratton (déc. 1996). "Identification du comportement non-linéaire des méso-constituants du Bloc300", Rapport d'avancement de contrat Aérospatiale .

[2] Y. Rémond (1984) "Sur la reconstitution du comportement mécanique d'un matériau composite 3D à partir de ses constituants", Thèse de 3éme cycle, Paris 6.

[3] J.P. Dumont, P. Ladevèze, M. Poss, Y. Rémond (1987). "Damage mechanics for 3D composites", Int. J. Composite II, 8, pp. 119-141.

[4] P. L. Héreil (Jan. 1997). "Comportement sous choc du composite 3D Carbone/Carbone BLOC300", Rapport provisoire de contrat Aérospatiale.

[5] .P. Ladevèze (1983), "Sur une théorie de l'endommagement anisotrope", Rapport interne L.M.T. $\mathrm{n}^{\circ} 34$.

[6] E. Sanchez-Palencia (1974)"Comportement local et macroscopique d'un type de milieux physiques hétérogènes" Int. Journ. Eng. Science - Vol. 12, pp. 331-351.

[7] J. VonNeumann and R. D. Rychtmyer (1950). "A Method for the Numerical Calculation of Hydrodynamic Shocks", J. Appl. Phys. Vol 21, pp. 232.

[8] L. Rayleigh (1910) "Aerial Plane Waves of Finite Amplitude", Proc.Roy.Soc. A84, pp.247.

[9] A. L. Jaumotte (1971). "Chocs et ondes de choc", Ed. Masson et Cie. 